\title{
Is there a fetal effect with low to moderate alcohol use before or during pregnancy?
}

\author{
Ian Walpole, Stephen Zubrick, Jacqueline Pontré
}

\begin{abstract}
Study objective-The aim was to investigate the effect of low or moderate alcohol consumption upon fetal outcome.

Design-This was a prospective randomised cohort study with mother and infant follow-up sample stratified on level of maternal alcohol intake.

Setting-A large maternity hospital in Western Australia.

Participants-2002 randomly selected pregnant women were recruited over a 3 year period for questionnaire survey (19 mothers refused participation). From 665 women in a stratified subsample selected on the basis of prepregnancy alcohol consumption, 605 newborns were available for study.
\end{abstract}

Investigation and main results-All 2002 women completed a comprehensive questionnaire on demographic, lifestyle (including diet), health, and obstetric factors. Of the 665 mothers who were followed through pregnancy, 605 liveborns were available at birth for measurement and detailed clinical evaluation. Low to moderate prepregnancy maternal alcohol intake was not associated with any untoward effect upon weight, length, head circumference at birth, or clinical wellbeing as indicated by Apgar score, respiratory distress syndrome, and overall clinical state. Other factors, particularly nicotine, were of much greater importance.

Conclusions-This study fails to show any significant relationship between low to moderate prepregnancy maternal alcohol intake and newborn clinical status. The outcome suggests that cautionary advice to pregnant women warning that any alcohol taken during pregnancy is potentially harmful to the fetus is inaccurate and therefore probably counterproductive.

Department of

Paediatrics, Princess

Margaret Hospital for

Children, Box D184,

GPO Perth, Western

Australia 6001

I Walpole

Health Department of

Western Australia,

Perth:

Neurosciences Unit

S Zubrick

Research and

Evaluation Unit

J Pontré

Correspondence to:

Dr Walpole

Accepted for publication May 1990 in assessing factors that influence pregnancy outcome in moderately drinking women. Self reporting of alcohol intake, variability of drinking patterns, and multiple beverages of differing strength complicate alcohol quantitation. ${ }^{8}$ Other confounding variables include physiological features such as body weight, maternal smoking environment, other drugs and beverages consumed, diet, general lifestyle, maternal health, and obstetric factors. ${ }^{79-13}$ Despite such acknowledged methodological difficulties several authoritative medical bodies have issued unequivocal statements saying that abstinence is the best policy and any alcohol taken in pregnancy is potentially harmful to the fetus. ${ }^{14-18}$ It is probably unlikely that such warnings have any effect on the at risk heavier drinking group of mothers. ${ }^{19-24}$ Such cautionary policy is not supported by the available scientific evidence and may have the effect of inducing or promoting guilt and suffering in a group of light or social drinking mothers, particularly when there has been a poor pregnancy outcome. ${ }^{12} 25-29$

The following prospective study was undertaken to investigate in detail a representative Australian population, mainly of moderate and social drinking pregnancy women, and to follow them through pregnancy. Newborn morphological data, birthweight, length and head circumference, and clinical status were used to evaluate birth outcome in relation to prepregnancy maternal alcohol consumption.

\section{Methods}

A full description of the method has been given elsewhere and a summary is provided here. ${ }^{30}$

\section{SUBJECTS}

Between January 1982 and December 1984 inclusive, 2002 consecutive pregnant women attending the public antenatal clinic of the main maternity hospital in Western Australia were recruited voluntarily to take part in the study. The women were not aware that the study was specifically related to alcohol consumption. Only 19 refused to participate. The majority $(58 \%)$ were in the first trimester of their pregnancy at the time of recruitment, $33 \%$ were in the second trimester, and $8 \%$ were in the third trimester. The demographic characteristics of the selected cohort were compared with the Western Australian general obstetric population. ${ }^{31}$ The sample contained a higher proportion of single mothers but otherwise was similar to the population of child bearing women in Western Australia. Subsequently, a sample of 605 motherinfant pairs was selected for follow up to obtain a 
resulting cohort of alcohol abstainers through to more heavily drinking women.

QUESTIONNAIRE PROCEDURE AND CONTENT

A questionnaire was completed by those 2002 mothers entering the study. ${ }^{\star}$ The aims and purpose of the study and confidentiality of answers were explained to respondents. A study researcher was available if required to help respondents with the questionnaire. Answers to the smoking and drinking items were retested in 50 mothers four to six weeks after completing the first questionnaire. Reliability coefficients of 0.87 and 0.85 respectively on those items were thought acceptable.

The questionnaire consisted of items assessing demographic characteristics, prepregnancy height and weight, past obstetric history and information on "life style" factors which included details of diet, smoking, drugs and medicines. Alcohol intake information was obtained to enable quantification of alcohol measures. The average amount of beer, wine and spirits consumed by each woman in the study was calculated. These volumes, when added together, resulted in the absolute alcohol score, ${ }^{32}$ and could also be used to derive Calahan's quantitative frequency-volume (QFV) and volume variability (VV) scores. ${ }^{33}$ As a guide, two drinks of spirits, two glasses of wine, or two cans of average strength beer contain about 28 $\mathrm{ml}(1 \mathrm{oz})$ of absolute alcohol.

Questions on smoking required the women to report how many cigarettes per day and which brand they usually smoked. Daily intake of nicotine (mg) was then calculated.

\section{SELECTION OF OBSTETRIC AND INFANT FOLLOW UP GROUPS}

On the basis of stratifying by alcohol intake prior to pregnancy, 665 pregnant women were selected from the cohort of 2002 to represent a wide spectrum of drinkers. Of the 665 pregnant women, 60 were lost to follow up because of miscarriage $(n=42)$, stillbirth $(n=12)$, or neonatal death $(n=6)$. We have already shown that there were no significant differences in mean cigarette and mean absolute alcohol consumption in women who had spontaneous abortion and stillbirths versus those with livebirths. ${ }^{30}$

Extensive maternal obstetric and medical details were obtained. ${ }^{30}$ Newborn clinical information, morphological data, and birth details were obtained by the same paediatrician, who was unaware of the maternal drinking status. Both physical examination and neurobehavioural assessment were performed between 24 and $72 \mathrm{~h}$ after birth unless the infant was preterm, in which case evaluation took place at the appropriate postconceptional age.

\section{DATA PREPARATION AND ANALYSES}

The major dependent variables of interest in this study included: birthweight, head circumference, birth length, Apgar scores at one and five minutes, and respiratory distress syndrome. The major control variables include: gestational age, parity, prepregnancy maternal weight, height, age and education, and nicotine consumption. The independent variable was recalled total daily absolute alcohol intake before pregnancy. The table shows the distribution of these variables.

In our study design and analyses, we attempted to anticipate potential problems in constructing statistical models due to measurement and specification error, multicollinearity and heteroscedasticity. ${ }^{34} 35$ The statistical treatment of choice was ordinary least squares multiple regression. ${ }^{34} 35$

The distributions of the independent variable (daily absolute alcohol consumption) and each dependent and control variable were examined for normality primarily to locate extreme cases and outliers. The distribution of absolute alcohol and nicotine was positively skewed owing to the number of women who abstained from drinking $(n=145)$ and smoking $(n=422)$. However, given the sample size and the relative robustness of multiple regression to violations of normality, we undertook no transformation of the data distributions. ${ }^{35} 36$

All models reported were further examined for possible multicollinearity by examining the tolerance of the independent variables entered in the model. The presence of heteroscedasticity was examined through analysis of residuals. We were satisfied that our data met the assumptions for analysis by multiple regression.

Each multiple regression proceeded in two steps. In step one the variance in the dependent variable of interest explained by the control variables was removed, and in step two absolute alcohol was entered.

\section{Results}

ADEQUACY OF FOLLOW UP SAMPLE

Several comparisons were made of the characteristics of the 665 mothers selected into the Summaries of study
variables

\begin{tabular}{|c|c|c|c|c|c|}
\hline & Mean & $S D$ & Median & Minimum & Maximum \\
\hline $\begin{array}{l}\text { Birthweight }(\mathrm{g}) \\
\text { Head circumference }(\mathrm{cm}) \\
\text { Birth length }(\mathrm{cm})\end{array}$ & $\begin{array}{r}3421 \cdot 9 \\
34 \cdot 8 \\
49 \cdot 7\end{array}$ & $\begin{array}{r}498.9 \\
1.4 \\
2.3\end{array}$ & $\begin{array}{c}\text { Dependent } \\
3390.3 \\
35.0 \\
50.0\end{array}$ & $\begin{array}{l}\text { bles } \\
2075 \\
32.5 \\
40.0\end{array}$ & $\begin{array}{r}5290 \\
43 \cdot 3 \\
60 \cdot 0\end{array}$ \\
\hline $\begin{array}{l}\text { Gestational age (weeks) } \\
\text { Parity (number) } \\
\text { Maternal weight (kg) } \\
\text { Maternal height (cm) } \\
\text { Age (years) } \\
\text { Education (level) } \\
\text { Nicotine (mg) }\end{array}$ & $\begin{array}{r}39.5 \\
2.2 \\
57.1 \\
162.9 \\
26.0 \\
4.6 \\
34.9\end{array}$ & $\begin{array}{r}1.4 \\
1.3 \\
9 \cdot 5 \\
7 \cdot 1 \\
5 \cdot 5 \\
1.0 \\
66.9\end{array}$ & $\begin{array}{r}\text { Control } \\
39.8 \\
1.9 \\
56.0 \\
162.9 \\
25.8 \\
4.6 \\
0.5\end{array}$ & les $\begin{array}{c}35 \\
1 \\
35 \cdot 4 \\
120 \\
14 \\
2 \\
0\end{array}$ & $\begin{array}{c}43 \\
7 \\
98 \cdot 0 \\
194 \\
50 \\
6 \\
385\end{array}$ \\
\hline Absolute alcohol & \multicolumn{5}{|c|}{$\begin{array}{l}\text { Independent variables } \\
0.14\end{array}$} \\
\hline
\end{tabular}


follow up cohort compared with those who were not selected. Significantly more of those followed up were married as opposed to single $\left(\chi^{2}=22.45\right.$; $\mathrm{df}=3 ; \mathrm{p}<0.001)$. Otherwise there were no significant differences in maternal height, weight, age, educational level, number of previous pregnancies, rate of cigarette smoking, and ethnicity for those chosen for follow up and those not chosen. In addition there were no significant differences in the level of alcohol consumption both before and during pregnancy for the mothers of children followed versus those not followed.

Overall we were satisfied that our sampling procedure yielded a follow up group that was representative of the population of women presenting at a major metropolitan maternity hospital.

\section{OUTCOMES}

Absolute alcohol

The table shows the distribution of the absolute alcohol score in the 605 selected women. In practical terms, $24 \%$ of the women were abstainers, $50 \%$ had daily average alcohol consumption of less than one drink, $12 \%$ consumed one to two drinks per day, 5\% consumed two to three drinks per day, $4 \%$ had three to four drinks, and $4 \%$ had over four drinks per day.

\section{Birthweight}

There was a significant association between birthweight and both maternal weight and nicotine consumption $\left(\mathrm{F}_{\mathbf{7 3 5 6}}=\mathbf{2 2 . 8} \mathrm{p}<0.0001\right.$; $R^{2}=0.22$ ), and when the effects of these variables were removed, there was no significant association between birthweight and absolute alcohol consumption $\left(F_{\text {change }}=1.9 ; p>0.05\right.$; $R^{2}=0 \cdot 23$ ).

\section{Birth length}

There was a significant association between birth length and gestation, maternal weight, and nicotine consumption $\left(F_{7536}=13.9 ; p<0.0001\right.$; $\left.R^{2}=0 \cdot 15\right)$. When the effects of these variables were removed, there was no significant association between birth length and absolute alcohol consumption $\left(F_{\text {change }}=1.49 ; p>0.05\right.$; $\mathbf{R}^{2}=0 \cdot 15$ ).

\section{Head circumference}

There was a significant association between head circumference and maternal weight and gestation $\left(F_{7536}=14.5 ; p<0.0001 ; R^{2}=0.15\right)$. When the effects of these variables were removed there was no significant association between head circumference and absolute alcohol consumption $\left(F_{\text {change }}=0.003 ; p>0.05 ; R^{2}=0.15\right)$.

\section{Apgar scores}

No significant associations were found between Apgar scores at one and five minutes and absolute alcohol consumption when adjusted for the control variables.

\section{Respiratory distress}

Fifty three infants were recorded as having mild to moderate respiratory distress (none was severe). There was a significant association between respiratory distress syndrome and gestation and nicotine consumption $\left(\mathrm{F}_{7536}=4 \cdot 13\right.$, $\left.\mathrm{p}<0.001 ; \mathrm{R}^{2}=0.05\right)$. When the effect of these variables was removed, there was no significant association between respiratory distress syndrome and level of absolute alcohol consumption $\left(F_{\text {change }}=0.03 ; p>0.05 ; R^{2}=0.05\right)$.

\section{Type of beverage}

Each of the above models was studied using the individual beverage scores for beer, wine or spirits in an attempt to determine whether type of beverage consumed had any specific effects on the reported dependent variables. As before, two step multiple regressions were employed adjusting for control variables, and then entering the beverage of interest.

No significant associations between birthweight, head circumference, birth length, Apgar scores and respiratory distress syndrome with beverage type were found.

\section{Discussion}

The data presented here indicate that newborns of mothers who drank light or moderate amounts of alcohol show no detrimental effects which can be attributed to such exposure. Public policy advising mothers that even small quantities of alcohol taken during pregnancy may potentially damage the fetus cannot be scientifically sustained and is likely to be counterproductive.

In excessive maternal alcohol intake it has long been observed that pre- and postnatal growth failure of weight, length, and head size are frequently seen, with an array of birth defects including a characteristic facies and psychomotor delay. ${ }^{2} 3738$ Reduction of in utero fetal growth is greater if heavy drinking is continued throughout pregnancy. ${ }^{39-41}$ Chronically alcohol dependent women who are more likely to have clinically evident alcohol affected newborns also have a high morbidity and mortality associated with an advanced stage of alcohol related disease. ${ }^{42-44}$ This present study, along with most other reports, fails to show any significant relationships between light and moderate maternal alcohol intake and fetal growth effect. These observations strongly support the views of Fabro who proposed that the adverse effects of alcohol in human fetal development follow a dose-response standard for teratogens. ${ }^{45}$

Of the cohort reported here, $49 \%$ were abstainers or light drinkers, $38 \%$ were moderate drinkers, and $13 \%$ consumed more than $28 \mathrm{ml}$ (1 oz) of absolute alcohol daily. This is similar to other Australian studies of obstetric populations. ${ }^{4647}$ It is within the latter group of mothers who drink excessively that real fetal risks exist.

\section{BIRTHWEIGHT AND LENGTH}

This and a number of other studies of moderate drinking mothers have not shown alcohol to have a significant impact on fetal growth. These studies have several different methodologies, particularly in relation to alcohol quantitation, timing of interview, and the way in which potential confounding factors are treated. ${ }^{12} 46-56$ 
In this study cofactors such as smoking and maternal weight prior to pregnancy were significantly related to fetal growth, whereas low to moderate maternal alcohol consumption was not. Smoking has been found to be a significant contributor to reduced fetal growth, although there is debate as to whether its effect is additive or potentiates the effects of higher alcohol consumption. 474951

Few studies have shown that light to moderate alcohol intake produces significant intrauterine growth retardation. A widely quoted study by Little $^{6}$ which concluded that an average maternal consumption of one ounce $(28 \mathrm{ml})$ of absolute alcohol daily would produce lower birthweight babies has been criticised on the basis that alcohol abusers could have accounted for most of the relationships discovered by the author. ${ }^{27} \mathrm{~A}$ later study by the same author reported similar more striking reductions in fetal growth with as little as $10 \mathrm{~g}$ of absolute alcohol per day prior to pregnancy. The results have not been reproduced in other studies and the authors stated the sample to be small and unusual. ${ }^{3}$

\section{HEAD CIRCUMFERENCE}

This study found that moderate maternal alcohol consumption was not associated with reduced head circumference and that maternal weight before pregnancy and gestation were the important variables. This has been true of other studies, and smoking has often been cited as another significant variable. ${ }^{12} 46-48505154-56$

Davis et al studied 973 white women attending a Warwickshire antenatal clinic and who completed a self administered questionnaire on social class, smoking, and consumption of a number of beverages, including alcohol during pregnancy. ${ }^{5}$ While admitting the limitations of the study methods, the authors still claim significantly reduced newborn head circumference in mothers who drank more than $20 \mathrm{ml}$ of alcohol per day. They also recommended abstention from alcohol as the only safe measure in pregnancy.

\section{NEWBORN CLINICAL STATUS}

Newborn infants in our study were fully evaluated. Apgar scores, respiratory distress syndrome, and the absence of any significant correlation with maternal alcohol consumption were chosen for particular comment. Nicotine was found to be significantly associated with untoward effects on the newborn, as has previously been reported. Others have reported a statistically significant, though clinically irrelevant, association with lower Apgar scores in the newborn of mothers who consumed more than two drinks a day. ${ }^{4854}$

\section{CONCLUSION}

In the attempt to tease out the aetiological association between alcohol and birth outcome, numerous methodological problems arise. They include many confounding variables such as maternal smoking, parity, ethnicity, gestation, socioeconomic status, weight at conception, diet, drug use and abuse, and medical and obstetric history. ${ }^{31030} 374657$ Of these factors, smoking is undoubtedly the most powerful and consistent predictor of low birthweight, and often the most difficult to control statistically because it is strongly related to alcohol consumption. We believe that the data presented in this study have addressed most of the above problems, particularly by being prospective, population based, and by considering the major possible outcome variables in detail.

With no specific biological alcohol marker, the problems of alcohol quantitation, pattern of drinking, and differences in beverages, which are all dependent upon self reporting, are well recognised. ${ }^{30}$ Heavy drinkers tend to underreport so that if fetal outcome of maternal alcohol drinking is observed against a sliding scale of rate of drinking this should mean merely a shift to left and not a loss of effect, if there is one to be observed. In this study alcohol quantitation was reliable, as it was assessed by retesting a cohort subgroup and by evaluating alcohol intake at a time when recall should have been more accurate and uninfluenced by a knowledge of outcome.

This study, like most similar studies, fails to show any significant relationship between low to moderate maternal alcohol intake and fetal outcome. Whether total abstinence is the best advice to pregnant mothers is therefore questionable. Where this knowledge or advice has been widely and successfully imparted to the community, those mothers in the heavier drinking groups continue to drink, ${ }^{39}$ while unnecessary guilt and anguish is engendered in light and occasional drinking women. ${ }^{122629404151}$

To recommend responsible drinking habits is not to advocate drinking in pregnancy. It is better to promote the idea that women should avoid binge and heavy drinking if they are planning for pregnancy. There should be greater emphasis on detecting the heavier drinking obstetric patient. Evidence indicates that appropriate early intervention can be effective in improving the prognosis for fetus and mother. ${ }^{4051}$

We wish to acknowledge the work of Dr Carmen Lawrence in providing this project with initial guidance and support. Our gratitude goes to Ms Sally Mullighan who was instrumental in meticulously gathering the data and assessing the infants. We would like to thank the staff and administration of King Edward Memorial Hospital for Women, Subiaco, Western Australia, for their full support. We thank Drs Carol Bower, Robert Finlay-Jones, Alison Garton, Jack Goldblatt and Fiona Stanley for their valued comments.

This research was in part supported by grants from TVW Telethon Foundation and the Princess Margaret Hospital for Children Medical Research Foundation.

1 Hanson JW, Jones KL, Smith DW. Fetal alcohol syndrome: experience with 41 patients. $\mathcal{F} A M A$ 1976; 235: 1458-60. 2 Clarren SK, Smith DW. The fetal alcohol syndrome. N Eng f Med 1979; 298: 1063-7.

3 Little RE, Asker RL, Sampson PD, Renwick JH. Fetal growth and moderate drinking in early pregnancy. $\mathrm{Am} f$ Epidemiol 1986; 123: 270-8.

4 Hanson JW, Streissguth AP, Smith DW. The effects of moderate alcohol consumption during pregnancy on fetal growth and morphogenesis. I Pediatr 1978; 92: 457-60.

5 Davis PJM, Partridge JW, Storrs CN. Alcohol consumption in pregnancy. How much is safe? Arch Dis Child 1982; 57 : in preg

6 Little RE. Moderate alcohol use during pregnancy and decreased infant birth weight. Am J Public Health 1977; 67: $1154-6$.

7 Landesman-Dwyer S. Drinking during pregnancy: effects on human development. In: National Institute on Alcohol Abuse and Alcoholism, Eds. Biochemical processes and consequences of and Alcoholism, Eds. Biochemical processes and consequences of alcohol (Alcohol and Health Monograph No 2),
D.C.: US Government Printing Office, 1982. 
8 Ernhart CB, Morrow-Tlucak M, Sokol RJ, Martier S. Under reporting of alcohol use in pregnancy. Alcoholism Clin $\operatorname{Exp}$ Res 1988; 12: 506-11.

9 Streissguth AP, Sampson PD, Barr HM, Clarren SK, Martin DC. Studying alcohol teratogenesis from the perspective of the fetal alcohol syndrome: methodological and statistical issues. Ann NY Acad Sci 1986; 477: 63-86.

10 Silva VA, Laranjeira RR, Dolnikoff M, Grindield H, Masur J. Alcohol consumption during pregnancy and newborn outcome. A study

11 Alpert JJ, Day N, Dooling E, et al. Maternal alcohol consumption and newborn assessment: methodology of the Boston City Hospital prospective study. Neurobehav Toxicol Teratol 1981; 3: 145-201.

12 Plant M. Women, drinking, and pregnancy (2nd ed). London: Tavistock Publications, 1987.

13 Edwards LE, Alton IR, Barrada MI, Hackanson EY. Pregnancy in the underweight woman: course, outcome and growth patterns of the infant. Am $₹$ Obstet Gynecol 1979; 135: 297-302.

14 U.S. Surgeon General. Surgeon General's advisory on alcohol and pregnancy. FDA Drug Bull 1981; 11: 9-10.

15 Royal Australasian College of Physicians. A position paper on alcohol abuse for fellows of the college and colleagues throughout the medical profession. Mod Med Aust 1983; 6: 39-40.

16 Australian Medical Association. Policy on alcohol consumption and abuse. Document No 317/1/87, adopted at the 26th Federal Assembly of the Association. 1987.

17 Australian College of Paediatrics. Policy statements; alcohol consumption in relation to pregnancy. Aust Paediatr $\mathcal{f}$ 1988; 24: 330 .

18 Pols RG, Hawks DV (eds). Is there a safe level of daily consumption of alcohol for men and women? Recommendations regarding responsible drinking behaviour. Canberra: NH and MRC, Australian Government Publishing Service, 1987.

19 Barrison IG, Waterson EJ, Murray-Lyon IM. Adverse effects of alcohol in pregnancy. $B r \mathcal{F}$ Addict $1985 ; 80: 11-22$.

20 Streissguth AP, Darby BL, Smith JR, Martin DC. Comparison of drinking and smoking patterns during pregnancy over a six year interval. Am f Obstet Gynecol 1983; 145: 716-724.

21 Raymond CA. Birth defects linked with specific level of maternal alcohol use, but abstinence still is the best policy. ЭAMA 1987; 258: 177-8.

22 Pierog S, Chandavasu O, Wexler I. The fetal alcohol syndrome: some maternal characteristics. Int $f$ Gynecol Obstet 1979; 46: 442-5.

23 Little RE, Grathwohl HL, Streissguth AP, McIntyre C. Public awareness and knowledge about the risks of drinking during pregnancy in Multnomah County, Oregon. Am $\mathscr{f}$ Pub Health 1981; 71: 312-4.

24 Fox SH, Brown C, Koontz AM, Kessel SS. Perceptions of risks of smoking and heavy drinking during pregnancy:

25 Kolata GB. Fetal alcohol advisory debated: some researchers question the government's advice that pregnant women do question the government's advice that pregn
not drink at all. Science 1981; 214: 642-5.

26 Roll DB, Smith T, Whelan EM. Alcohol use during pregnancy: What advice should be given to the pregnant pregnancy: What advice should be given to the
woman? Adv Alcohol Substance 1983; 2:61-7.

27 Abel EL. Fetal alcohol effects: advice to the advisers. Alcohol Alcoholism 1985; 20: 189-93.

28 Rosett HL, Weiner L. Prevention of fetal alcohol effects. Pediatrics 1982; 69: 813-6.

29 Leak AM. Alcohol and the fetus. Lancet 1983; i: 984

30 Walpole I, Zubrick S, Pontré J. Confounding variables in studying the effects of maternal alcohol consumption before and during pregnancy. $\mathcal{f}$ Epidemiol Community Health 1989; 43: 153-61.

31 Australian Bureau of Statistics Publication. Birth Australia, Catalogue Number 3301.0, 1981.

32 Jessor R, Graves RD, Hanson RC, Jessor SL. Society, personality and deviant behaviour: a study of triethnic
community. New York: Holt, Rinehart and Winston, 1968.
33 Cahalan D, Cisin I, Crossley H. American drinking practices: a natural study of drinking behavior and attitudes. New Brunswick, NJ: Rutger Center of Alcohol Studies, 1969.

34 Cohen J, Cohen P. Applied multiple regression for the behavioral sciences. New York: Wiley, 1975.

35 Berry WD, Feldman, S. Multiple regression in practice. Beverly Hills: Sage Publications, 1985.

36 Bohrnstedt GW, Carter TM. Robustness in regression analysis, In: Costner HL, ed. Sociological methodology. San analysis, In: Costner HL, Jossey-Bass, 1971.

37 Plant ML, Plant MA. Family alcohol problems among pregnant women: links with maternal substance use and pregnant women: links with maternal substance use and

38 Ernhart CB, Sokol RJ, Martier S, et al. Alcohol teratogenicity in the human: A detailed assessment of specificity, critical period and threshold. Am $\mathcal{f}$ Obstet Gynecol 1987; 156: 33-9.

39 Little RE, Streissguth AP, Barr HM, Herman CS Decreased birth weight in infants of alcoholic women who abstained during pregnancy. $₹$ Pediatr 1980; 96: 974-7.

40 Rosett HL, Ouelette EM, Weiner L, Owens E. Therapy of heavy drinking during pregnancy. $\mathcal{F}$ Obstet Gynecol 1978; 51: 41-6.

41 Rosett HL, Weiner L. Commentary: Prevention of fetal alcohol effects. Pediatrics 1982; 69: 813-6.

42 Clarren SK, Bowden DM. Fetal alcohol syndromes: a new primate model for binge drinking and its relevance to human ethanol tolerance. $f$ Pediatr 1982; 101: 819-25.

43 Véghelyi PV, Osztovics M, Kardos G, Leisztner L Szaszouvszky E, Gali S, Imrei J. The fetal alcohol Szaszouvszky E, Gali S, Imrei J. The fetal alcohol syndrome: symptoms

44 Majewski F. Alcohol embryopathy, some facts and speculations about pathogenesis. Neurobehav Toxicol Teratol 1981; 3: $129-44$

45 Fabro S. In utero alcohol exposure: threshold for effects? A medical letter. Reprod Teratol 1982; 1: 11-14.

46 Gibson GT, Baghurst PA, Colley DP. Maternal alcohol, tobacco and cannabis consumption and the outcome of preonancy. Aust NZ 7 Obstet Gynaecol 1983; 23: 15-19.

47 Lumley J, Correy JF, Newman NM, Curren JT. Cigarette smoking, alcohol consumption and fetal outcome in Tasmania. Aust NZ f Obstet Gynaecol 1985; 25: 33-40.

48 Sulaiman ND, Florey C du V, Taylor DJ, Ogston SA. Alcohol consumption in Dundee primigravidas and its effects on outcome of pregnancy. Br Med $\mathcal{F} 1988 ; 296$ : effects

49 Wright JT, Barrison IG, Lewis IG, et al. Alcohol consumption, pregnancy and low birthweight. Lancet 1983, i: $663-5$.

50 Kuzma JW, Sokol RJ. Maternal drinking behaviour and decreased intrauterine growth. Alcohol Clin Exper Res 1982; 6: 396-402.

51 Hingson R, Alpert JJ, Day $\mathrm{N}$, et al. Effects of materna drinking and marijuana use on fetal growth and development. Pediatrics 1982; 70: 539-46.

52 Kaminski M, Franc M, Lebouvier M, du Mazaubrun C, Rumeau-Rouquette C. Moderate alcohol use and pregnancy outcome. Neurobehav Toxicol Teratol 1981; 3: $173-81$.

53 Mills JR, Graubard BI, Harley EE, Rhoads GS, Berendes HW. Maternal alcohol consumption and birthweight. HW. Maternal alcohol con

54 Streissguth AP, Martin DC, Martin JC, Barr HM. The Seattle longitudinal prospective study on alcohol and pregnancy. Neurobehav Toxicol Teratol 1981; 3: 223-33.

55 Mau G. Moderate alcohol consumption during pregnancy and child development. Eur $\mathcal{F}$ Pediatr 1980; 133: 233-7.

56 Tennes K, Blackard K. Maternal alcohol consumption, birthweight and minor physical anomalies. Am $\mathcal{f}$ Obstet Gynecol 1980; 138: 774-80.

57 Ounsted M, Scott A. Associations between maternal weight, height, weight for height, weight-gain and birthweight. In: Dobbing J, ed. Maternal nutrition in pregnancy, eating for two? New York: Academic Press, 1984: 113-29.

58 Weiner L, Larsson G. Clinical prevention of fetal alcohol effects. Evidence for effectiveness of intervention. Alcohol Health Res World 1987; 11: 60-94. 